\title{
MODELOS DE NEGÓCIOS, BIBLIOTECAS E LIVROS DIGITAIS
}

\author{
Liliana Giusti Serra* \\ José Eduardo Santarém Segundo*
}

RESUMO O estudo discute os modelos de negócios para licenciamento de livros digitais por bibliotecas com o objetivo de identificar suas características e possibilidades de aplicação. A partir de revisão de literatura realizada com recorte temporal de 2011 a 2016 , são identificados os fornecedores de conteúdo digital para bibliotecas (editores, distribuidores e agregadores). Os modelos de negócios são apresentados, com destaque de características e implicações para a gestão dos acervos, principalmente no tocante ao desenvolvimento de coleções, onde o processo de licenciamento acarreta em perda de controle dos títulos presentes nas coleções. Os modelos analisados compreendem as possibilidades de licenciamento perene e transitório, exemplificadas nas formas de contratação por Aquisição perpétua, Assinatura, Aquisição Orientada ao Usuário (DDA), Empréstimo de Curto Prazo (STL) e Seleção Baseada em Evidência (EBS). No âmbito dos modelos transitórios são destacadas as possibilidades de aplicação de aluguel de conteúdos realizados com vistas a atender demandas imediatas dos usuários. $O$ estudo analisa o licenciamento oferecido a leitores identificado como "Netflix dos livros" e suas possibilidades de utilização. O fracionamento de livros digitais é abordado, com a oferta de capítulos de livros, proporcionando possibilidades de aplicação em bibliotecas. Como resultado, espera-se fornecer subsídios aos agentes envolvidos com o livro digital com o intuito de orientação na identificação e seleção dos modelos de negócios adequados às necessidades de instituições e possibilidades de contratação de conteúdo. O estudo conclui que os agentes relacionados aos livros digitais devem participar nas propostas, decisões e análises de modalidades de licenciamento, visando alcançar um equilíbrio.

Palavras-chave: Livro digital. Conteúdo licenciado. Modelos de negócios. Desenvolvimento de coleções.

\footnotetext{
* Mestre em Ciência da Informação pela Universidade de São Paulo, Brasil. Doutoranda no Programa de Pós-Graduação em Ciência da Informação na Universidade Estadual Paulista Júlio de Mesquita Filho, Brasil. Especialista em Gerência de Sistemas pela Fundação Escola de Sociologia e Política de São Paulo, Brasil. Profissional da informação na empresa Prima (SophiA Biblioteca).

E-mail: Igiustiserra@gmail.com.

** Doutor em Ciência da Informação pela Universidade Estadual Paulista Júlio de Mesquita Filho, Brasil. Docente e coordenador do Curso de Graduação em Ciências da Informação e da Documentação e Biblioteconomia da Faculdade de Filosofia, Ciências e Letras de Ribeirão Preto da Universidade de São Paulo, Brasil. Docente do Programa de Pós-Graduação em Ciência da Informação da Universidade Estadual Paulista Júlio de Mesquita Filho, Brasil. Coordenador do GT8 - Informação e Tecnologia, da Associação Nacional de Pesquisa e Pós-Graduação em Ciência da Informação, Brasil.

E-mail: santarem@usp.br
}

\section{INTRODUÇÃO'}

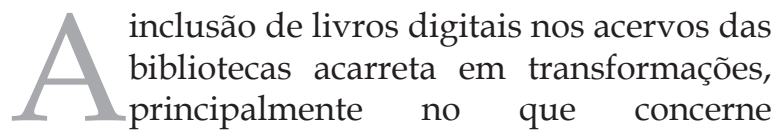

I Trabalho colocado em primeiro lugar no 6o. Congresso Internacional CBL do Livro Digital de 2016. ao processo de licenciamento de conteúdo. Em relação aos livros impressos, os digitais apresentam desafios e oportunidades que afetam o desenvolvimento de coleção, o acesso à informação e a aquisição, especialmente por englobar diversas modalidades de contratação. Anteriormente, ao selecionar uma publicação, a mesma era adquirida e entregue pelo fornecedor, registrada e disposta no catálogo 
da biblioteca para que pudesse ser utilizada pelos usuários, sem definição da quantidade de acessos que a publicação poderia ter. A partir do momento que uma obra estivesse registrada no catálogo, a mesma poderia ser consultada por diversas vezes, sem necessidade de pagamentos recorrentes ou prazo para renovação de licença de uso. Com o advento do livro digital esta situação foi alterada, com a possibilidade de inclusão temporária de títulos no catálogo. Estas obras poderão ser consultadas por período de tempo pré-determinado ou sem prazo de vencimento estabelecido e, de acordo com a forma de contratação realizada, aportes financeiros podem ser necessários, representando investimentos recorrentes na manutenção da coleção.

Observa-se no Brasil o mesmo movimento de inclusão de livros digitais ocorrido nas bibliotecas dos Estados Unidos e Europa, com a contratação de publicações digitais iniciandose por instituições de ensino superior com posterior ampliação ao ambiente corporativo, bibliotecas públicas e escolares, atendendo público infanto-juvenil. Em decorrência disto, a quantidade de títulos disponíveis no Brasil para licenciamento por bibliotecas é composta essencialmente por conteúdo universitário ou profissional, enquanto aos leitores, nas livrarias virtuais, estão presentes títulos para variadas faixas etárias, nas modalidades ficção e não ficção, em oferta superior. Apesar das bibliotecas poderem adquirir livros digitais em livrarias virtuais, estas ferramentas são construídas com foco no leitor, com o download da publicação sendo realizado em dispositivo de leitura, com restrições para transferência do arquivo aos usuários ou armazenamento em servidores ou repositórios institucionais. Assim, as bibliotecas contratam livros digitais licenciados por meio de fornecedores específicos que permitem o acesso ao conteúdo através de plataforma na Web, com o valor do licenciamento sendo calculado de acordo com o modelo de negócio contratado e a quantidade de acessos simultâneos estabelecida.

$\mathrm{Na}$ medida em que ocorre o aumento da oferta de títulos e novas possibilidades para licenciamento são oferecidas, dúvidas são apresentadas às bibliotecas sobre qual modelo de negócio pode ser empregado e suas características. As possibilidades de contratação de livros digitais por bibliotecas não estão completamente estabelecidas até o momento, com modalidades sendo lançadas por fornecedores ou ainda observando variações em modelos existentes que acabam por culminar em novas formas de contratação. Apresentar os modelos de negócio para bibliotecas é, portanto, o objetivo deste artigo, com o intuito de subsidiar os agentes envolvidos sobre elementos que nortearão a formação e curadoria da coleção digital.

\section{MÉTODO DE PESQUISA}

Esta pesquisa bibliográfica analisa referencial teórico selecionado em livros, dissertações, artigos de periódicos, trabalhos de eventos e sítios da Web sobre os aspectos relacionados às formas de licenciamento de livros digitais realizados por bibliotecas. Os modelos de negócios são analisados com o intuito de identificação de elementos que os caracterizam, com base em relatos de experiências que elencam benefícios e dificuldades encontradas.

Dentre o material consultado destacase a produção em inglês, com recorte temporal remetendo ao período compreendido entre 2011 e 2016.

A possibilidade de contratação por meio de aluguel também foi analisada porém, como é uma modalidade desenvolvida com foco nos leitores, sua análise será realizada com a perspectiva de eventual adoção em bibliotecas, caso venha a se estabelecer como um modelo de negócio atrativo a fornecedores e consumidores. A oferta de capítulos de livros digitais para bibliotecas também é discutida, visto que vislumbra-se a possibilidade de licenciamento específico destes recursos informacionais.

A identificação dos fornecedores de conteúdo digital para bibliotecas é realizada com o intuito de delinear os agentes envolvidos no mercado, visto que as ofertas de produtos e serviços influenciará na escolha do modelo a ser adotado. 


\section{FORNECEDORES DE LIVROS DIGITAIS PARA BIBLIOTECAS}

As bibliotecas adquirem livros digitais essencialmente de três tipos de fornecedores: editores, distribuidores e agregadores de conteúdo. Os autores não foram contemplados neste conjunto, pois as iniciativas de aquisição com o autor que aderiu à auto-publicação ainda não são expressivas em bibliotecas e, quando ocorrem, usualmente estão vinculadas com a plataforma da ferramenta utilizada (muitas vezes em lojas virtuais) ou ainda a contratação é realizada por compra direta com o autor e transferência do arquivo à instituição.

No âmbito dos livros digitais, independentemente do fornecedor escolhido, a leitura será mediada por uma plataforma que deve assegurar proteção e controle de acesso aos títulos, inibindo tentativas de utilização não autorizada dos conteúdos. O desenvolvimento destas plataformas é custosa aos fornecedores e, até o momento, não foram localizadas discussões acerca de estabelecimento de padrões mínimos ou funcionalidades, cabendo a cada desenvolvedor a escolha das possibilidades de uso e serviços que serão oferecidos.

Os editores são profissionais do livro e representam os autores, proporcionando estrutura editorial, de divulgação, distribuição e venda dos títulos. A editora agrega valor ao conteúdo, proporcionando uma chancela à obra, de acordo com sua presença e relevância no mercado editorial. Os títulos de uma editora podem ser comercializados por ela mesma ou ainda por meio de terceiras partes como distribuidores e agregadores de conteúdo.

Os distribuidores comercializam os títulos de editores e agregadores, agindo como intermediários e, portanto, representando custos superiores no licenciamento. A vantagem na contratação de distribuidores centra-se na facilidade de concentrar a escolha de títulos de diferentes editores, proporcionando economia de tempo e recursos financeiros à biblioteca, afinal, de acordo com a quantidade de títulos contratados, pode-se negociar descontos.

Os agregadores de conteúdo surgem no cenário do livro digital diferenciando-se dos distribuidores por possuírem plataformas de leitura (RONCEVIC, 2013). Também representam títulos de diversas editoras e os oferece às bibliotecas, porém o acesso ao conteúdo será proporcionado pela sua própria plataforma. Sua ferramenta proporciona segurança ao editor e pode possuir serviços e produtos atrativos aos usuários, como impressão, leitura off-line (download do arquivo), aquisição total ou parcial do conteúdo pelo usuário etc. Seu vínculo com a biblioteca ocorrerá durante todo o período do licenciamento, não se encerrando na entrega do produto contratado, como ocorre com o distribuidor.

Algumas editoras já oferecem seu catálogo de livros digitais em solução própria, porém nem todas investiram no desenvolvimento de uma plataforma. Nestes casos, é possível oferecer seus títulos a um agregador de conteúdo. Mesmo possuindo uma plataforma própria, o editor também pode dispor seus títulos por meio de um agregador de conteúdo, aumentando suas chances de vendas. O distribuidor comercializa títulos de editores e agregadores e, ao encerrar o processo de contratação, entrega os livros digitais nas plataformas oferecidas pelos fornecedores de cada título. Às bibliotecas é interessante a contratação de títulos por meio de agregadores, visto que eles possuem extensa quantidade de títulos e condições atrativas de contratação decorrente do volume de obras oferecidas para licenciamento. As possibilidades de contratação de fornecedores por bibliotecas estão representadas na Figura 1. 
Figura 1: Fornecedores de livros digitais para bibliotecas

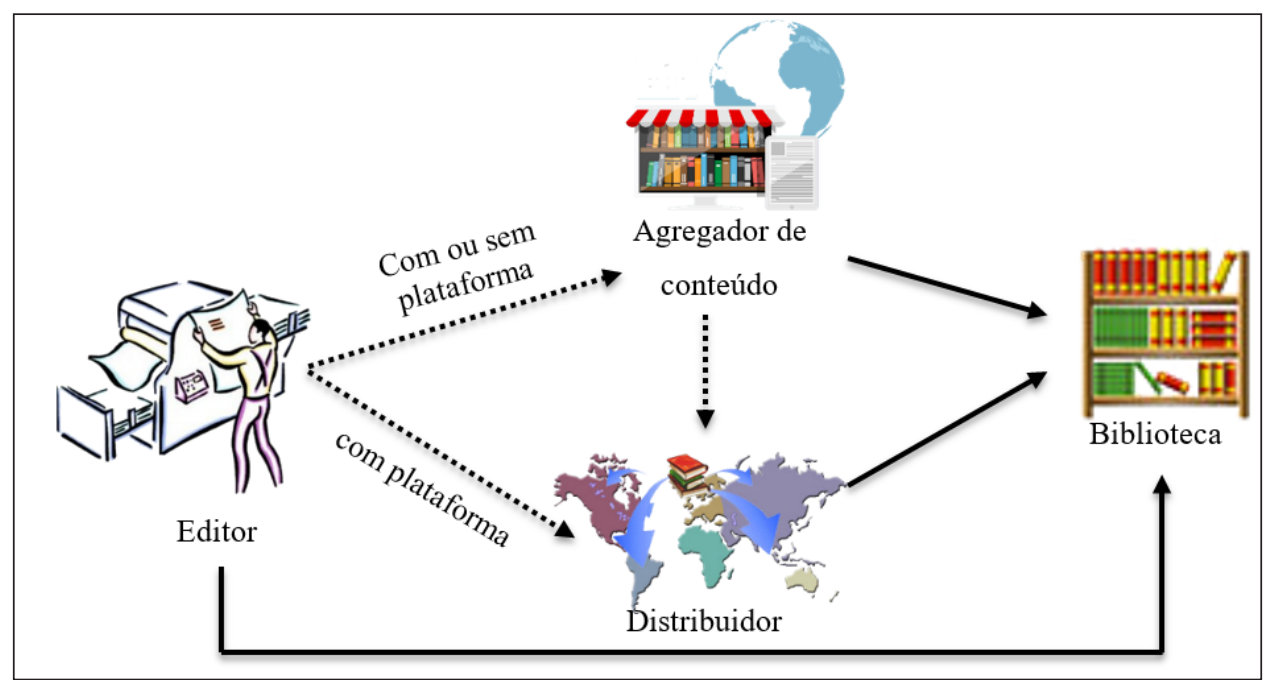

Fonte: elaborado pela autora

No momento da contratação a escolha dos títulos pode ser individual ou por pacotes, formados por diversas obras. O fornecedor privilegia a oferta de pacotes, organizados por temáticas, que reúnem diversos títulos que são licenciados em conjunto, sem possibilidade de seleção pela biblioteca. Esta situação contribui para o aumento da oferta de títulos a custos menores, uma vez que a contratação individual possui valores mais altos. Por outro lado, não permite flexibilização ou autonomia da biblioteca para montar sua coleção, situação questionada pelas bibliotecas.

Os pacotes possuem diversidade de obras, resultando em um único contrato para licenciar muitos títulos, porém neste conjunto nem todas as publicações serão relevantes, afinal podem existir obras de editores desconhecidos ou de baixo interesse dos usuários, sem contar a variedade da qualidade das publicações presentes. Também pode ocorrer a contratação de obras concorrentes, decorrente da oferta dos catálogos das editoras a diversos agregadores e distribuidores, resultando em redundância que somente será interessante à biblioteca caso o título apresente alta incidência de consulta.

A contratação de pacotes pode proporcionar agilidade na atualização de títulos que apresentem modificações de conteúdo frequentes - áreas da saúde, jurídicas e tecnológicas, por exemplo - e isto deve ser considerado pelas bibliotecas que possuem acervos que sofrem atualizações constantes (GRIGSON, 2011). Por outro lado, segundo Morris e Sibert (2011), a substituição das edições existentes por novas representa uma fragilidade, pois a biblioteca não pode assegurar aos seus usuários que disponibilizará ao menos um exemplar em edições antigas. É evidente que substituir edições antigas por atuais representa uma rápida atualização do acervo, porém, nem sempre uma nova edição terá qualidade igual ou superior da edição anterior. Os estudos de evolução dos temas, acompanhados por edições das publicações, ficam comprometidos, sem a garantia de perpetuidade do conteúdo para pesquisa. Assim, as bibliotecas tornar-se-ão locais de informação atualizada, sem a manutenção e a preservação da história de seus registros bibliográficos (SERRA, 2015).

As bibliotecas realizam licenciamento com diversos fornecedores, afinal dificilmente todas as publicações solicitadas serão contratadas por um único instrumento. $\mathrm{O}$ fornecedor pode não cobrir todas as áreas do conhecimento, resultando em contratações pontuais para suprir demandas da coleção. Títulos podem ser restritos, obrigando o licenciamento com fornecedores específicos. Embora ocorram em menor quantidade, casos de embargos ainda são relatados, com editores 
permitindo a oferta de lançamentos após um prazo pré-determinado. A prática do embargo representa uma restrição, com a biblioteca sendo obrigada a esperar meses para poder realizar o licenciamento de um título em sua forma digital.

Outro fator de destaque é a possível ocorrência de quebra ou não renovação do contrato entre autores e editores, ou ainda, entre editores e agregadores. Apesar das obras poderem ser oferecidas por outro editor/ fornecedor em caso de não renovação ou quebra de contrato, a transferência das publicações para outro representante não é imediata e pode resultar na indisponibilidade das mesmas até que questões legais sejam estabelecidas. Também pode ocorrer restrição de comercialização de obras, com o descredenciamento de editores com agregadores de conteúdo, com remoção dos títulos das plataformas e, consequentemente do acervo da biblioteca, de forma arbitrária. Esta situação pode ser observada inclusive na contratação realizada por aquisição perpétua, ou seja, apesar de realizar uma contratação sem necessidade de renovação do licenciamento, a biblioteca pode ter uma obra removida da coleção em decorrência de rompimentos contratuais entre autores e fornecedores. Além disso, deve ser observada a situação de autores que estando sem contratos têm, consequentemente, suas obras indisponíveis para comercialização ou, por encontrarem-se esgotadas, não podem ser licenciadas. Estes são alguns aspectos que fragilizam o controle da coleção, com a definição dos títulos que farão parte do acervo sendo delegada aos fornecedores, e decorrente da aplicação de modelos de negócios para realização do licenciamento.

Alguns fornecedores trabalham com poucos modelos, enquanto outros oferecem diversas possibilidades. Os modelos transitórios são oferecidos usualmente pelos agregadores de conteúdo, provavelmente pela expressiva carteira de títulos presentes em suas plataformas, aumentando as possibilidades de contratação e uso de conteúdo digital. Nestes modelos o acesso aos livros digitais é suspenso a partir do momento em que não ocorre a renovação, tornando inacessíveis todo o conjunto contratado. Observa-se, portanto, que os modelos de negócios possuem características que afetam o desenvolvimento de coleções, a partir do momento que a biblioteca tenha o conteúdo licenciado removido, cancelado, suspenso ou indisponível, sem a interferência ou, até mesmo, sem a ciência do bibliotecário.

Os modelos de negócios mais utilizados no Brasil são Aquisição perpétua e Assinatura, porém existem outras modalidades transitórias em aplicação como Demand Driven Acquisition (DDA, Aquisição Orientada por Demanda, tradução nossa), Short Term Loan (STL, Aluguel de Curto Prazo, tradução nossa) e Evidence-Based Selection (EBS, Seleção Baseada em Evidência, tradução nossa).

\section{MODELOS DE NEGÓCIOS}

Atualmente são identificados dois tipos de modelos de negócios: o perene, permanente ou sem data para expirar; e os modelos transitórios, que exigem pagamentos recorrentes para acesso do conteúdo (SERRA, 2015). A escolha do modelo a ser adotado define o padrão de investimentos que serão realizados. No modelo perene o custo de licenciamento é alto, com relatos de cobranças superando as edições impressas. Na contratação transitória os investimentos são recorrentes, porém sem a garantia de manutenção do título em longo prazo, com sua remoção podendo ocorrer em casos de não renovação contratual.

A Aquisição perpétua é um modelo perene, com a remuneração do licenciamento ocorrendo uma única vez, sem necessidade de renovação. Entretanto, este modelo pode apresentar pagamentos recorrentes aos fornecedores, uma vez que o conteúdo foi licenciado, porém é necessário manter o acesso à plataforma onde ocorre a leitura (ALBITZ; BRENNAN, 2012; GRIGSON, 2011), cuja manutenção pode exigir ajustes financeiros periódicos.

A Aquisição perpétua reproduz o processo de compra de obras impressas ao permitir à biblioteca a seleção da publicação desejada e sua inclusão no acervo. Este modelo deve ser empregado para títulos que a biblioteca quer assegurar que permanecerão por longo prazo na coleção (DOUCETTE; LEWONTIN, 2012; NATIONAL INFORMATION STANDARDS ORGANIZATION, 2014). Também se mostra vantajoso para os títulos que são bastante demandados pela comunidade atendida, com grande incidência de acessos. Por outro lado, a prática de preços altos, com valores superando 
as publicações impressas, pode comprometer o orçamento disponível para crescimento e manutenção do acervo. Aos fornecedores não é um modelo interessante, decorrente dos riscos de distribuição descontrolada e uso indevido, além de representar queda nas vendas, com a biblioteca adquirindo o acesso ao título e não diversos exemplares impressos.

Os modelos transitórios são assim identificados pois, exigem um pagamento periódico, que pode ser calculado por uma unidade de tempo ou de acordo com a quantidade de acessos ao conteúdo que foi realizada. Alguns modelos podem ser interpretados como alugueis, onde a biblioteca desembolsa uma quantia percentual do valor da obra para atender a uma demanda que, dependendo da quantidade de solicitações recebidas, pode iniciar de forma automática um processo de licenciamento por outras modalidades. Embora estejam em desenvolvimento, com variações sendo oferecidas pelos fornecedores, a aplicação dos modelos transitórios mostra-se uma tendência ao permitir acesso a diversos títulos a custos mais baixos.

No licenciamento por Assinatura é realizada a contratação de títulos de livros digitais em grandes quantidades, dentro de um período determinado e com custos baixos, sem que ocorra a propriedade da publicação, mas um acesso temporário (MORRIS; SIBERT, 2011). De acordo com Albitz e Brennan (2012), como o conteúdo é alugado e não adquirido, a biblioteca não possui garantias que os títulos estarão disponíveis de forma permanente, representando, assim, que as assinaturas não fornecem estabilidade. As renovações dos licenciamentos ocorrem em períodos regulares, normalmente uma vez ao ano. Nestes momentos serão cobrados valores para manutenção dos títulos existentes e inclusão de novos, ou ainda atualizações. Para Morris e Sibert (2011), as assinaturas são arriscadas aos fornecedores, uma vez que as bibliotecas podem encontrar dificuldades na manutenção dos contratos de licenciamento ou continuidade dos títulos nos acervos. Ao renovar regularmente uma contratação, a biblioteca mantém um investimento constante sem, contudo, aumentar a oferta de títulos. "Pode-se dizer que a assinatura de livros digitais foi o primeiro modelo transitório apresentado. Sua oferta foi decorrente da experiência com as publicações seriadas e com as bases de dados, não sendo, portanto, uma contratação desconhecida das bibliotecas" (SILVA; SERRA, 2016, p. 882).

Os modelos DDA, STL e EBS são alternativas de licenciamento interessantes, pois a biblioteca pode optar pelo uso esporádico, franqueando aos seus usuários o acesso à obras não pertencentes à coleção. Nestes modelos o fornecedor permite que todos os títulos de seu catálogo sejam consultados pelos usuários, com a cobrança sendo computada de acordo com os acessos realizados. Assim, o usuário tem inúmeras publicações a seu alcance, praticamente como se fosse uma livraria. Para a biblioteca ocorre ampliação do acervo. Ao pagar somente pelos títulos que foram utilizados, é realizada economia dos recursos, com aumento da oferta de fontes, sem investimento em obras que não serão consultadas repetidamente. Também facilita a identificação de títulos cujo interesse dos usuários seja sazonal ou desconhecido, investindo somente no que for solicitado, contribuindo com a diminuição de esforços de aquisição de obras que apresentam baixa demanda de consulta. Este cenário contribui ainda com conhecimento dos usuários e na estipulação de diretrizes para estabelecimento de políticas de desenvolvimento de coleções. Estas modalidades mostram-se atrativas principalmente para bibliotecas universitárias e corporativas, onde a realização de pesquisas e projetos são frequentes. Às demais bibliotecas são interessantes ao fornecerem quantidade expressiva de títulos, porém suas aplicações podem mostrar-se limitadas em decorrência dos licenciamentos transitórios realizados, cujos valores são elevados, principalmente se a solicitação aos títulos for realizada por poucos usuários.

O DDA assegura uma ampla oferta de títulos aos usuários, com a remuneração do fornecedor ocorrendo após utilização das obras acessadas. Seu emprego pode ser mediado e limitado por um conjunto de regras, e contemplar um gatilho que dispara o licenciamento transitório ou permanente. O bibliotecário pode incluir todas as obras do fornecedor para consulta, ou então selecionar quais títulos não licenciados serão disponibilizados para consulta. É possível incluir critérios dos títulos que podem ser acessados como: 1) tipo de conteúdo; 2) data de publicação; 3) assunto; 
4) editor; 5) país de publicação; 6) preço; 7) idioma; 8) apenas lançamentos; e 9) formato (NATIONAL INFORMATION STANDARDS ORGANIZATION, 2014). A partir de uma quantidade de acessos (alugueis) realizados, a obra passa a fazer parte da coleção da biblioteca, em processo de licenciamento que ocorre de forma automática.

A seleção dos títulos que serão incluídos no acervo é delegada ao usuário, com o bibliotecário podendo definir recortes ou restrições das obras que podem ser acessadas, ou ainda moderando as solicitações. Com os processos de compra sendo disparados por acessos realizados no catálogo na Web, a biblioteca pode ter seu orçamento comprometido caso os usuários não recebam orientações sobre como utilizar os serviços oferecidos. Ao bibliotecário será necessário o acompanhamento das solicitações e utilizações feitas, identificando títulos e formas de licenciamento empregados, visando o melhor aproveitamento dos investimentos realizados para o crescimento do acervo. $\mathrm{O}$ acompanhamento de métricas é fundamental, visando identificar títulos que possuem alta procura e que devem ser adquiridos por modelos que permitam uso em longo prazo, ou inclusão de títulos que são alugados recorrentemente em pacotes de assinaturas, ou ainda o aluguel de obras para usos pontuais, sem necessidade de inclusão do título no conjunto dos livros digitais contratados (SERRA, 2015).

O DDA é um modelo que pode ser aplicado para livros impressos e digitais, embora com estes últimos sua popularidade tenha sido ampliada, encontrando possibilidades para sua utilização. De acordo com Swords (2011), o DDA surgiu em decorrência da diminuição do orçamento de bibliotecas, enaltecendo a importância de realizar aquisições de publicações que sejam utilizadas de forma recorrente, atendendo às demandas dos usuários. O modelo pode ser utilizado em conjunto com as demais modalidades, como Aquisição perpétua ou Assinatura, quando o título é incluído ao acervo após ultrapassar a quantidade estipulada de acessos possíveis, ou o STL, realizando aluguéis do título sempre que for solicitado pelo usuário.

O STL permite que os títulos sejam consultados por curtos períodos de tempo, sem a necessidade de aquisição permanente do conteúdo, mas por meio de um aluguel. É uma evolução do DDA. Ao solicitar o acesso a um título não licenciado, o usuário (e apenas ele) poderá consultar a obra temporariamente por um período de locação. A remuneração pelo uso é realizada de acordo com a quantidade de acessos realizados e o tempo que o material fica à disposição do usuário e é variada de acordo com o fornecedor, com relatos de acessos de 24 horas ou 48 horas (DOUCETTE; LEWONTIN, 2012), intervalo de dias, semanas (POTER; WEAVER; NEWMAN, 2012) ou meses (NATIONAL INFORMATION STANDARDS ORGANIZATION, 2014). Os custos do licenciamento temporário variam de 10 a $20 \%$ do valor da obra solicitada segundo Grigson (2011), de 10 a 15\%, para Morris e Sibert (2011) ou de 10 a 30\% de acordo com Rapp (2011b apud WEAVER; NEWMAN, 2012). Para Grigson (2011) o custo do aluguel pode ser considerado caro, afinal a biblioteca está beneficiando somente um usuário, sem aumentar a oferta de títulos aos demais. Por outro lado, não é feito um investimento de longo prazo em um título que representa baixo interesse. Ao bibliotecário cabe analisar que, caso ocorram outras solicitações do mesmo título, se não é adequado inclui-lo no pacote de publicações licenciadas e alterar sua forma de contratação, aplicando condições de licenciamento mais baratas que as praticadas com o STL. Quando feito por longos prazos, o aluguel representa um investimento alto. Nestas situações, a biblioteca deve ponderar se não se mostra vantajoso realizar um licenciamento por período maior, ao invés de realizar diversos alugueis curtos. O modelo também possibilita a manutenção da prática do Empréstimo Entre Bibliotecas (EEB), uma vez que é permitido ao usuário a utilização temporária de uma obra externa ao acervo (GRIGSON, 2011), facilitada pela ausência de custos para deslocamento dos volumes impressos pelo correio ou por meio de portadores.

Como o aumento do número de alugueis realizados pode vir a diminuir a quantidade de licenciamentos perenes realizados, para Verma (2014), o STL não é atraente aos fornecedores, por representar menor remuneração pelo uso do conteúdo. Esta situação pode comprometer o modelo caso ocorram aumentos nos valores, prática que pode ser adotada por fornecedores com o objetivo de cobrir custos do serviço e compensar queda nas vendas. Embora não 
tenham sido identificados casos semelhantes na literatura consultada, outra alternativa seria a aplicação do STL para contratação temporária de obras, em prazos inferiores aos praticados nas assinaturas, com acesso permitido por períodos de três a seis meses. Esta demanda decorre de procura por conteúdos de forma sazonal, essencialmente nos âmbitos acadêmico e corporativo, em decorrência de pesquisas e estudos em curso. Nestas situações, alguns títulos podem ser demandados, porém a quantidade de solicitações recorrentes em longo prazo é desconhecida e optar por um licenciamento perene ou transitórios como a assinatura ou o DDA pode não ser interessante. Ao poder realizar empréstimos de médio prazo, as bibliotecas poderiam garantir o acesso a títulos de interesse sem realizar o licenciamento perene dos mesmos, até assegurar-se que constituem obras de uso recorrente. Evidentemente são necessários acompanhamentos de indicadores de uso para proporcionar aos bibliotecários evidencias seguras de que um conjunto de títulos justifica um investimento de longo prazo (aquisição perpétua), médio prazo (uso semestral) ou curto prazo (alugueis).

O EBS proporciona à biblioteca a garantia de que os investimentos da instituição estão centrados em livros digitais realmente utilizadas pelos usuários, e contribui com o melhor uso dos recursos disponíveis. Neste modelo o fornecedor disponibiliza por um período determinado, normalmente um ano, todo o seu catálogo para utilização dos usuários, com cobrança de valor estimado da quantidade de acessos que serão realizados. Ao término deste prazo, a biblioteca fará aquisição perpétua dos títulos que foram mais consultados, selecionados com base nas estatísticas de uso. Assim, é minimizado o risco de realizar uma aquisição de obras que foram acessadas por um ou poucos usuários. Caso não ocorram muitos acessos, a biblioteca realizará a aquisição de títulos que não foram consultados, mas que denotam interesse do acervo, alcançando o valor acordado na contratação, garantindo remuneração ao fornecedor.

Segundo Levine-Clark (2015), o modelo representa riscos tanto ao fornecedor quanto à biblioteca. Se não forem realizados muitos acessos, publicações que não foram usadas serão adquiridas para cumprir o contrato assinado. Por outro lado, os usuários podem acessar mais obras do que a quantidade contratada, não ocorrendo remuneração proporcional ao fornecedor. Uma alternativa é o estabelecimento de limites mínimo e máximo e, após o término do contrato, garantir um acerto razoável entre as partes.

Os modelos existentes continuam a sofrer transformações, com fornecedores e bibliotecas buscando melhores alternativas para o licenciamento e utilização dos conteúdos. Com a publicação de uma orientação da National Information Standards Organization (NISO), sobre o DDA em 2014, reforça-se o entendimento de que este modelo de negócios vem crescendo nas bibliotecas estrangeiras, vindo a firmar-se como uma opção para inclusão de livros digitais aos acervos. Embora ainda existam muitas variações, com fornecedores estabelecendo critérios próprios para licenciamento e utilização de livros digitais, espera-se que este modelo tenha seu emprego expandido, principalmente pela flexibilidade na contratação (SERRA, 2015).

Observa-se que os modelos de negócios não são novidades somente para bibliotecas, mas para fornecedores, que também estão testando possibilidades de licenciamento de conteúdo. Os modelos precisam proporcionar um balanço entre fornecedores, bibliotecas e usuários, pois todos são afetados. Se o editor não lança livros digitais, as bibliotecas não podem adquiri-los. Se os custos de licenciamento são muito altos, a aquisição fica impossibilitada. Se a biblioteca não remunera o fornecedor pelos títulos utilizados, este não terá condições de atuar no mercado, encerrando seus serviços. Se os fornecedores impõem muitas barreiras tecnológicas para proteger seu conteúdo irão dificultar o acesso do usuário, e este procurará outras fontes ou recorrerá a artifícios não legalizados para acessar os livros digitais. Se as bibliotecas não conseguem oferecer livros digitais aos usuários, estes recorrerão a livrarias ou, novamente, a meios ilegais para obtenção de conteúdos. Os modelos de negócios devem ser desenvolvidos e estabelecidos de forma a atender a todos os elos da cadeia de consumo do livro digital, caso contrário não terão sua perpetuação garantida. É preciso observar as evoluções das discussões e oferta de serviços e relatos de casos de bibliotecas, com o objetivo de estabelecer parâmetros de contratação padronizados entre os fornecedores, facilitando a gestão das bibliotecas e utilização por parte dos usuários. 


\section{SERVIÇOS DE ALUGUEL E FRAGMENTAÇÃO DE CONTEÚDO}

$\mathrm{Na}$ indústria do entretenimento foram oferecidos serviços que alteram a forma tradicional de contratação e acesso a conteúdos, com o streaming ou a licença de uso substituindo a compra. As possibilidades de remuneração estão transformando a oferta de produtos e serviços - essencialmente nos campos da música, cinema e televisão - oferecendo aos consumidores opções legalizadas de acesso aos conteúdos, em valores acessíveis. Este movimento não elimina a pirataria, mas pode proporcionar queda na distribuição não autorizada de conteúdo, a partir do momento em que o material desejado pode ser contratado a preços baixos e acessados de forma rápida e simples, por meio de dispositivos. Seguindo o movimento de produtos culturais, em 2013 foram lançados os serviços de aluguel de livros.

Inicialmente identificados como "Netflix dos livros", estes serviços foram oferecidos aos leitores e não às bibliotecas. Empresas como Oyster Books, Scribd, Entitle, Blloon etc. ofereceram acesso a diversos livros a um custo baixo, a partir de acordos com editores e autores - optantes por serviços de auto-publicações. Aos leitores era possível realizar contratação por quantidade de livros que poderiam ser lidos mensalmente ou ainda, a opção de acesso ilimitado. As plataformas assemelham-se a redes sociais, formando clubes de leitura, com a sugestão de livros entre os leitores, estimulando o consumo das obras.

Em 2015 boa parte das empresas citadas acima encerraram seus serviços, levando à conclusão que o serviço de aluguel de livros não é uma modalidade interessante para contratação de conteúdo. $\mathrm{O}$ fator determinante para o fracasso das experiências foi a remuneração entre as partes. Em alguns casos, os autores e editores eram pagos por proporção de leitura realizada nas plataformas dos serviços. Se a leitura fosse realizada em mais de $10 \%$ da obra, ocorria o pagamento da totalidade da publicação, comprometendo o lucro do serviço prestado. As empresas de aluguel teriam ganhos realizados com base nos leitores esporádicos, garantindo menor remuneração aos editores e autores, visto que o leitor pagou, porém não consumiu a totalidade contratada em seu pacote. Os leitores vorazes, por outro lado, representam prejuízos. Ao tentarem estipular limite de obras acessadas mensalmente, estes serviços encontraram resistência por parte destes leitores. A concorrência do serviço oferecido pela Amazon, o Kindle Owners's Lending Library, também comprometeu a manutenção destas empresas, com a possibilidade de acesso gratuito a livros digitais aos leitores que possuem um dispositivo Kindle. Fechando este cenário, a desconfiança na remuneração, poucos editores aderindo à modalidade e a ausência de grandes editoras e lançamentos culminaram por tornar a manutenção do serviço de streaming de livros insustentável. Os primeiros relatos de experiências com este modelo demonstram que ele não durou nem amadureceu tempo suficiente para ser testado por bibliotecas. Esta iniciativa não foi identificada no Brasil.

É necessário, entretanto, avaliar se o streaming é uma alternativa para oferta de livros digitais. Primeiramente a leitura não possui as mesmas características dos demais produtos como músicas, filmes ou seriados de televisão. As canções possuem, em média, quatro minutos. Seriados de televisão tem episódios com variações entre 30 e 60 minutos. Filmes possuem cerca de duas horas de duração. Livros possuem quantidade variada de páginas e o tempo de leitura é ditado pelo leitor. Este fato permite que o consumo de audiovisuais seja célere em relação aos livros, com muitos itens sendo consumidos durante o período contratado, proporcionando ao consumidor sensação de que está usufruindo do serviço. Outro aspecto é o esforço dispensado. Produtos da indústria audiovisual exigem menor concentração em comparação à leitura. Assistir filmes ou escutar música são ações passivas, que podem ser interrompidas ou serem realizadas em ambientes com ruídos. Também podem ser consumidos durante a execução de outras atividades, como dirigir ou conversar. A leitura, por outro lado, demanda postura ativa do leitor, em local adequado, sem interrupções ou ruídos, embora nem todos os leitores necessitem de silencio. Enquanto a música e o cinema são experiências coletivas, o ato de ler é solitário, visto que a velocidade de leitura é distinta entre leitores, assim como seu nível de envolvimento e concentração (SERRA, 2016). 
Estes aspectos talvez contribuam para o entendimento do fracasso do modelo de streaming de livros para leitores, porém o serviço é interessante para bibliotecas. Os produtos culturais ainda estão experimentando este modelo e é necessário aguardar sua evolução e a oferta de produtos para identificar se o streaming é de fato uma alternativa de remuneração interessante ou se não encontrará terreno fértil no mercado editorial.

Outro fator que tem sido observado é a fragmentação de conteúdo. Este movimento foi observado na música, com a comercialização de canções ao invés de álbuns, discos ou CDs, e também é notado em seriados de televisão, com o consumidor podendo licenciar um episódio ou toda uma temporada de seu seriado favorito. No âmbito dos livros este movimento não é novo e, inclusive, já sofreu restrições por incorrer em violação de direitos autorais, principalmente no meio estudantil, com professores criando pastas com os conteúdos que serão utilizados em sala de aula. Ao selecionar a literatura necessária para abordar uma disciplina, professores separam artigos, capítulos, livros e demais publicações que, nem sempre, serão utilizadas em sua totalidade. Aos estudantes era oferecida a possibilidade de reprografia dos conteúdos, acarretando em diminuição da quantidade de obras comercializadas, além de não remuneração a editores e autores. A legislação de direitos autorais do Brasil, Lei no. 9610, de 1998, não permite a reprodução total de obras e limita em $10 \%$ o montante que pode ser copiado. É, portanto, inexistente a opção de aquisição parcial de conteúdo.

Com os livros digitais observa-se esta possibilidade de comercialização, com remuneração proporcional em detrimento de pagamento total da publicação. Esta opção flexibiliza aos estudantes o acesso aos conteúdos de forma legal e garante aos fornecedores e autores a remuneração pelo material consumido. Alguns fornecedores de conteúdo digital já oferecem esta opção a seus clientes. Recentemente o agregador de conteúdo Minha Biblioteca passou a oferecer a bibliotecas e aos estudantes o serviço "Pasta do Professor", onde capítulos podem ser contratados pela biblioteca e comercializados aos usuários finais.

Ainda é prematuro afirmar que este modelo perdurará entre os fornecedores do mercado editorial, afinal o pagamento parcial pode não ser atrativo, acarretando em ganhos granulares, comprometendo a manutenção do negócio. Por outro lado, é uma alternativa interessante, pois, além de inibir a pirataria, garante remuneração ao fornecedor que, até então, era inexistente. Evidentemente pode proporcionar queda nas vendas de publicações completas mas, por outro lado, permite o recebimento da fração que foi consumida podendo, inclusive, proporcionar aos editores indicativos de temas de interesse para lançamento de novos produtos. Às bibliotecas pode vir a ser uma forma para ampliação de seu acervo ou aplicação de descontos em renovações contratuais, caso receba comissionamento sobre as transações realizadas por seus usuários, uma vez que eles tiveram acesso à compra diretamente com os fornecedores contratados.

A fragmentação, portanto, pode ser vista como uma tendência. Um indicativo desta afirmação é decorrente de capítulos de livros digitais serem identificados por mecanismos como o Digital Object Identifier (DOI, Identificador de Objeto Digital, tradução nossa), ressaltando a possibilidade de aumento de sua oferta para licenciamento.

\section{CONCLUSÃO}

O cenário dos livros digitais está em processo de estabelecimento, com as opções de licenciamento sendo testadas entre bibliotecas e fornecedores. É imperativo que as bibliotecas participem da construção destas rotinas, garantindo sua autonomia na formação da coleção, liberdade para realizar empréstimos e possibilidades de licenciar publicações por variadas formas de contratação, com aplicação de preços justos e acessíveis. O uso de livros digitais é um aspecto importante a ser analisado no desenvolvimento de coleções. Neste contexto, as bibliotecas devem garantir ao seu público o acesso aos conteúdos, à informação e à cultura. Para tanto, o quadro corrente do mercado editorial e os modelos de negócios para o livro digital não podem ser um empecilho para as bibliotecas cumprirem suas missões essenciais, que estão centradas na preservação dos acervos e sua disponibilização aos usuários.

Analisando os modelos de negócios e suas implicações no desenvolvimento de coleções, 
observa-se que os livros digitais representam fragilidade na manutenção de títulos no acervo em longo prazo, mesmo que o conteúdo seja licenciado como Aquisição perpétua. Isto é decorrente dos contratos realizados entre autores, editores, distribuidores e agregadores de conteúdo onde, caso ocorram rescisões ou não renovação de contratos entre as partes, resultam na impossibilidade de comercialização e, provavelmente, remoção dos títulos. Como os fornecedores somente podem disponibilizar títulos que estejam ativos em suas plataformas, caso não ocorra uma renovação contratual os itens podem ficar indisponíveis. A mesma situação pode ser empregada a títulos esgotados. Se o livro digital não está disponível para licenciamento, os fornecedores não podem incluílos ou mantê-los em seus pacotes.

O modelo perene Aquisição perpétua proporciona familiaridade aos bibliotecários ao emular o processo de aquisição semelhante ao utilizado com publicações impressas. Porém, seus custos ainda são altos, representando fortes investimentos na formação do acervo. Os modelos transitórios representam desafios a partir do momento em que os usuários podem acessar os livros digitais diretamente no catálogo na $W e b$ e, dependendo da forma de licenciamento contratada, definirem os títulos que serão adquiridos em longo prazo. Ainda é uma modalidade desconhecida dos bibliotecários e não são muito conhecidos no Brasil, com exceção da Assinatura. Entretanto, proporcionam flexibilidade no uso do orçamento para aquisição de publicações, assegurando investimento nos títulos efetivamente demandados pelos usuários, minimizando riscos de compras com baixa procura. A oferta de serviços de aluguel de livros, identificados como "Netflix dos livros", possui semelhança com o modelo de negócio STL. Cabe avaliar se a adoção de streaming se consolidará como uma opção e, caso isto ocorra, se será expandida para bibliotecas, visto que foram construídas com foco nos leitores finais, em semelhança às livrarias virtuais, que exigem o download dos livros em dispositivos, dificultando sua utilização em bibliotecas.

A possibilidade de oferta de conteúdo fragmentado passa a ser uma alternativa, principalmente nas bibliotecas universitárias, cujo consumo de capítulos é recorrente. Para tanto, a remuneração pelo uso deve ocorrer de forma proporcional, não representando os custos da obra completa, mas pagando somente pelo montante que foi utilizado. Esta opção garante aos fornecedores e à biblioteca a remuneração somente do conteúdo que foi efetivamente consumido, proporcionando economia de recursos. Expandir aos usuários da biblioteca a possibilidade de licenciamento de conteúdo diretamente com o fornecedor é uma alternativa interessante. Ao usuário é facilitado o acesso, ao fornecedor é garantida a transação comercial e à biblioteca pode proporcionar comissionamento das tratativas comerciais realizadas, resultando em novos investimentos em conteúdo.

É necessário aguardar a acomodação dos fornecedores e as possibilidades de contratação que existem e as que vão surgir na economia digital, com a biblioteca posicionando-se perante os fornecedores, ocupando sua área de atuação e mantendo seu papel social, cultural e educacional perante a sociedade. Com aumento da oferta de títulos disponíveis para bibliotecas e flexibilização dos modelos de negócios, esperase alcançar uma situação que seja benéfica aos interessados no segmento editorial, promovendo o emprego de livros digitais nos acervos em situação de equilíbrio.

Os resultados esperados com este estudo centram-se na possibilidade de fornecer subsídios aos agentes envolvidos no âmbito das bibliotecas na identificação e seleção dos modelos de negócios para licenciamento de conteúdo digital, bem como, melhor explorar as possibilidades de utilização dos recursos contratados. 


\section{BUSINESS MODELS, LIBRARIES AND EBOOKS}

ABSTRACT This paper discusses the business models for licensing digital books by libraries with the proposal of identify their characteristics and application possibilities. From literature review, with time frame 2011 to 2016, are identified the digital content providers for libraries (publishers, distributors and content aggregators) and their procedures. The business models are presented, highlighting their characteristics and implications in the library management, particularly as regards the collection development, where the licensing process leads to a frailty as the loss of control about the titles present in the collections. The analyzed models covers the perennial and transitory licensing, exemplified in hiring models as Perpetual Acquisition, Signature, Demand Driven Acquisition (DDA), Short Term Loan (STL) and Evidence Based Selection (EBS). Under the transitory models are highlighted the possibility of content loan, made in order to meet immediate demands of patrons. The study also analyzes the licensing option offered by readers identified as "Netflix for books" and its possible uses. Fractionation of digital books is approached with the offer of book chapters, providing other applications possibilities in libraries. As a result, the study expected to provide subsidies to agents involved in the digital book with the guidance in the identification and selection of business models tailored to the needs of institutions and content hiring. The study concludes that all agents related to digital books should participate in the proposals, decisions and analysis of licensing arrangements in order to achieve a balance between those involved.

Key words: $\quad$ Ebook. Licensed content. Business models. Collection management.

\section{REFERÊNCIAS}

ALBITZ, Becky; BRENNAN, David. Budgeting for e-books. In: KAPLAN, Richard (ed). Building and managing e-book collection. Chicago: NealSchuman, 2012. p.85-94.

DOUCETTE, Joanne; LEWONTIN, Amy. Selecting e-books. In: KAPLAN, Richard (ed). Building and managing e-book collection. Chicago: Neal-Schuman, 2012. p.51-74.

GRIGSON, Anna. An introduction to e-book business models and suppliers. In: PRICE, Kate; HAVERGAL, Virgina (Ed.). E-books in libraries: a practical guide. London: Facet, 2011. p. 19-36.

LEVINE-CLARK, M. Evidence-based selection at the University of Denver. Against the grain, Charleston, v. 27, n. 5, p. 18-20, 2015. Disponível em: <http:/ / www.against-the-grain.com/wpcontent/uploads/2015/12/fea_levine-clark_v275.pdf>. Acesso em 05 jan. 2016.

MORRIS, Carolyn; SIBERT, Lisa. Acquiring e-books. In: POLANKA, Sue (ed.). No shelf required: e-books in libraries [recurso eletrônico]. Chicago: American Library Association, 2011. Cap. 6.

NATIONAL INFORMATION STANDARDS ORGANIZATION. Demand Driven Acquisition of monographs [recurso eletrônico]. Baltimore (MD): NISO, 2014. Disponível em:< http:/ / www. niso.org/publications/rp/rp-20-2014>. Acesso em 30 jun. 2014.

POTER, Michael; WEAVER, Matt; NEWMAN, Bobbi. E-book sea change in public libraries. In: POLANKA, Sue (Ed.). No shelf required 2: use and management of electronic books [recurso eletrônico]. Chicago: American Library Association, 2012. Cap.9.

RONCEVIC, Mirela. E-book platforms for libraries. Library Technology Reports, Chicago, v. 49, n. 3, p.5-42, abr. 2013.

SERRA, Liliana Giusti. As bibliotecas e os serviços de aluguel de livros digitais. In: PRADO, Jorge (org.). Ideias emergentes em biblioteconomia [recurso eletrônico]. São Paulo: Febab, 2016. p.93-98. Disponível em: <https:// 
ideiasemergentes.files.wordpress.com/2016/03/ ideiasemergentesembiblioteconomia2.pdf >. Acesso em: 26 maio 2016.

\section{Os livros eletrônicos e as}

bibliotecas. 2015. Dissertação (Mestrado em Cultura e Informação) - Escola de Comunicações e Artes, Universidade de São Paulo, São Paulo, 2015. Disponível em: <https://doi. org/10.11606/d.27.2015.tde-01122015-101516>. Acesso em: 26 maio 2016.

SILVA, José Fernando Modesto da; SERRA, Liliana Giusti. Livros digitais licenciados e os modelos de negócios transitórios. In:
International Conference on Information Systems \& Technology Management, 13., 2016, São Paulo. Anais... São Paulo: FEA/USP, 2016. p. 878-893. Disponível em: http:// doi. org/10.5748/9788599693124-13CONTECSI/PS3786. Acesso em: 30 ago. 2016.

SWORDS, David A. (ed.). Patron-driven acquisitions. [S.1.]: De Gruyter Saur, 2011. 205 p. (Current topics in library and information practice).

VERMA, H. Short-term loan, long-term. Library Journal, New York, v.139, n. 18, p. 18-20, 2014. 